\title{
DIURNAL CYCLE OF PRECIPITABLE WATER VAPOR OVER SPAIN
}

\author{
J. P. Ortiz de Galisteo1, 2, V. Cachorro1, C. Toledano', B. Torres', N. Laulainen³, Y. Bennouna', A. \\ de Frutos ${ }^{1}$
}

1 GOA-UVA, Group of Atmospheric Optics, University of Valladolid, Spain.

${ }^{2}$ AEMET, Meteorological State Agency, Territorial Delegation of Castilla y León, Spain.

${ }^{3}$ PNNL, Pacific Northwest National Laboratory, Richland, WA, USA.

\author{
Corresponding Author: \\ J. P. Ortiz de Galisteo \\ e-mail: jportiz@goa.uva.es
}

Keywords: PWV; atmospheric water vapor content; diurnal regime; GPS.

\begin{abstract}
Knowledge of the diurnal cycle of precipitable water vapor (PWV) is very limited due to the lack of data with sufficient temporal resolution. Currently, GPS receivers have proven to be a suitable technique to determine the PWV diurnal variations. In this study, the annual and seasonal diurnal cycles of PWV have been obtained from GPS data for ten locations over Spain. The minimum value of PWV is reached approximately at the same time at all the stations, 0430-0530 UTC, whereas the maximum is reached in the second half of the day, but with a larger dispersion of its occurrence between stations. The annual sub-daily variability ranges from 0.41 to $1.35 \mathrm{~mm}(3-7 \%)$. The highest values are recorded at the stations on the Mediterranean coast, with a doubling of the values of the stations on the Atlantic coast or inland. The winter cycle is quite similar at all locations, whereas in summer, local effects are felt strongly, making the diurnal cycle quite different between stations. The PWV mean diurnal cycle is strongest in summer and weakest in spring, with a sub-daily variability of 1.34 and 0.66 $\mathrm{mm}$ respectively. Harmonic analysis shows that the first two harmonics can explain $97 \%$ of the variance. The diurnal (24h) harmonic explains $85 \%$ of the variance, has mean amplitude of $0.40 \mathrm{~mm}$, and the peak time is from early afternoon to evening. The semidiurnal (12h) harmonic is weaker, with amplitude of $0.13 \mathrm{~mm}$, and peak time between 0400-1000 UTC. The diurnal cycle of temperature alone would be a proxy for PWV cycle during the night, but not during daytime. The breeze regime is the main factor responsible for the phase lag between PWV and temperature cycles during daytime. No clear correlation between the daily cycle of precipitation and PWV has been found.
\end{abstract}

\section{Introduction}

Precipitable water vapor (PWV) is the most abundant greenhouse gas, and plays a crucial role in many atmospheric processes such as radiative balance, hydrological cycle, the transport of large amounts of latent heat energy or instability and convective activity. Thus, precise knowledge of PWV distribution is important in meteorology for both, numerical weather forecasting and climatological studies. Nevertheless, and despite its importance, knowledge of its behavior is very limited due to the lack of data with sufficient spatial and temporal resolution.

Considering the high temporal and spatial variability of PWV, the conventional observing systems are not suited to provide sufficient information. Thus, additional PWV data from new observation techniques are highly desirable to achieve adequate observation coverage. In recent years many networks of GPS ground receivers have been established, from which PWV can be measured (Bevis et al., 1992). Such instruments provide data with high temporal resolution in all weather conditions and all hours of the day. This allows the systematic study of the diurnal cycle of this atmospheric component, which can be applied to a better modeling of the water vapor attenuation of the direct solar radiation (Jakobson et al., 2009) and of the physical parameterizations in numerical weather models.

The determination of PWV from GPS receivers is based on the delay produced by the atmosphere in the arrival time of the signal of the GPS satellites. This delay can be divided into ionospheric and tropospheric components. The ionospheric delay is dispersive, such that the GPS satellites emit in two frequencies in order to quantify and remove this effect in the propagation of the signal (Spilker, 1980; Brunner and Gu, 1991). On the other hand, the troposphere is non-dispersive. In this layer, the delay is determined by the refractive index along the path of the signal. The refractivity of the atmosphere is a function of temperature, pressure, and water vapor content. Water vapor is a unique atmospheric gas in the troposphere having its own dipolar 
momentum that contributes to the dipolar component of the atmospheric refractivity. Thus, the zenith tropospheric delay (ZTD) can be divided into a hydrostatic (ZHD) component, associated with the dipolar momentum induced in the atmosphere; and a wet delay (ZWD) component, associated with the permanent dipolar momentum of water vapor (Saastamoinen, 1972). ZHD is an order of magnitude larger than ZWD, but ZWD is usually far more variable. Thus, the daily variability of ZWD usually exceeds that of ZHD by an order of magnitude (Elgered et al., 1991). From measurements obtained by GPS system and by use of complex inversion algorithms, the ZTD can be calculated (Tralli and Lichten, 1990; Herring et al., 1990; Rocken et al., 1993; Duan et al., 1996). The ZHD can be modeled knowing the atmospheric pressure at surface. Subtracting the ZHD from the ZTD, the ZWD is obtained, which can be transformed into PWV knowing the water- vapor-weighted mean temperature of the atmosphere. This can be derived from the temperature at the station level (Davis et al., 1985; Bevis et al., 1992). Approximately $1 \mathrm{~mm}$ of PWV produces a $6.35 \mathrm{~mm}$ delay, but this factor can vary by about $20 \%$ with respect to location, altitude, season of the year, and meteorological conditions (Bevis et al., 1994). Thus, a GPS network can be used to estimate the PWV (de Haan, 2006).

The quality of GPS PWV data has been demonstrated through intercomparison with different instruments and techniques (Ohtani and Naito, 2000; Bokoye et al., 2003; Schneider et al., 2009). In addition, on November 6, 2006, the International GNSS Service adopted an absolute calibration model for the antennas of the GPS satellites and receivers instead of the relative one. This change has involved an improvement, increasing the accuracy of station position determination, and, consequently, benefiting post-processing products, such as ZTD and PWV (Ortiz de Galisteo et al., 2010). Some authors have compared the PWV diurnal cycle from GPS and microwave radiometer (MWR) data. They suggest that GPS are suitable for studying the diurnal variations of PWV (Dai et al., 2002; Morland et al., 2009).

\section{Methodology and data}

The GPS stations on the Spanish mainland as a part of EUREF (European Reference Frame; http://epncb.oma.be/) have been used in this study. In order to the study has a climatologic character, only the stations with the longest series of data have been selected. These stations are: Coruña, Alicante, Almería, Cáceres, Santander, Creus, Roquetes, San Fernando, Valencia, and Villafranca (Table I). The stations of Coruña and Santander are located on the north Atlantic coast; San Fernando on the south Atlantic coast (near the Strait of Gibraltar); Alicante, Almería, Creus, Roquetes and Valencia are situated on the Mediterranean coast; and Cáceres and Villafranca inland (Fig. 1). Due to the geographical situation of Spain between two seas with different characteristics, the Atlantic Ocean and the Mediterranean Sea, and to its abrupt and complicated physical relief with several mountain ranges, valleys of large rivers, and two large plateaus, several areas with different PWV climatologies can be expected.

The GPS data have been processed by the Geographic National Institute of Spain (IGNE) for all stations. The selected stations have data from August 2001; however, only the data from January 2002 to December 2008 have been used to avoid any kind of bias for not considering whole years. The ZTD data have hourly frequency and have been calculated using the software, Bernese V5.0, with the precise orbits of the satellites provided by the IGS (International GNSS Service). The ZTD data were transformed into PWV according to the procedure described by Bevis et al. (1992). For that, the pressure at surface level $P_{s}$ and the water vapor weighted mean temperature of the atmosphere $T_{m}$ (Davis et al., 1985) are required. $T_{m}$ was computed from the surface temperature $T_{s}$ from the expression $T_{m}=61.9+0.75 T_{s}$. (1) instead of a similar expression obtained by Bevis et al. (1992). This expression was obtained based on the analysis of 37,179 radiosonde profiles spanning a 9-year interval from seven radiosonde stations over the Iberian Peninsula. The linear regression has a bias of $0.06 \mathrm{~mm}$ and a root mean square error (rmse) of $3.19 \mathrm{~mm}$. A comparison between the $T_{m}$ computed from $T_{s}$ and the $T_{m}$ from the soundings was carried out at 00 and 12 UTC, to check the possible artificial diurnal cycle in PWV introduced by the $T_{m}-T_{s}$ relationship, because this takes no account of the fact that $T_{s}$ has a much higher diurnal cycle amplitude than temperatures higher in the atmosphere (Wang et al., 2005). A dry bias in $T_{m}$, and subsequently in PWV, was obtained at night, and a wet bias at daytime. At 00 UTC Eq. (1) underestimated the $\mathrm{T}_{\mathrm{m}}$ by $1.08{ }^{\circ} \mathrm{K}$, and at 12 UTC Eq. (1) overestimated the $\mathrm{T}_{\mathrm{m}}$ by $1.09{ }^{\circ} \mathrm{K}$. That means a variation of $\sim 2{ }^{\circ} \mathrm{K}$ produces an artificial mean difference in PWV between those hours around $1 \%$. This difference will be higher between the peak hours of the maximum and minimum $\mathrm{T}_{\mathrm{s}}$. To remove this artificial cycle, the $\mathrm{T}_{\mathrm{s}}$ was damped according with the expression $\mathrm{T}_{\mathrm{sd}}=$ $0.25 \mathrm{~T}_{\mathrm{s}}+0.75 \mathrm{~T}_{\mathrm{sm},}(2)$ where $\mathrm{T}_{\mathrm{sm}}$ is the daily mean surface air temperature (Morland et al., 2009).

Meteorological data $\left(P_{s}\right.$ and $\left.T_{s}\right)$ for each station were obtained from the nearest station of the Spanish Meteorological State Agency (AEMET). There is a meteorological station in the same city for all the GPS stations except San Fernando, Villafranca and Creus. For the first two the meteorological station is $25 \mathrm{~km}$ away and for the third, it is $50 \mathrm{~km}$. If needed, we have corrected the meteorological data by the difference of altitude between the GPS and the meteorological stations. Temperature data are hourly, but there are only four pressure data per day. To avoid introducing an artificial PWV cycle, the 6-hourly pressure data were interpolated at the ZDT hours taking into account the barometric tide, which presents over Spain a semidiurnal cycle with maximum values of the atmospheric pressure around 1000 and 2200 UTC and minimum ones around 0400 and 1600 UTC, with mean amplitude of $0.5 \mathrm{mb}$ (Ray and Ponte, 2003). PWV calculation is very sensitive to pressure uncertainties; an error of 0.5 $\mathrm{mb}$ in pressure produces $1 \%$ error in PWV (Hagemann et al., 2003).

To calculate the diurnal cycle we proceeded as follows. First, we calculated the mean PWV for each day by averaging the 24 hourly data. Subsequently, the hourly anomalies for each day were obtained subtracting the daily mean from the hourly PWV values. In this manner, the mean contribution to the PWV due to the synoptical situation is removed, with only the contribution of the factors which vary following a diurnal cycle remaining (Jakobson et al., 2009). Finally, the annual mean diurnal cycle of each station was obtained by averaging for each hour the anomalies of all days. A similar procedure was used to obtain the seasonal cycles. But in this case a diurnal cycle for each month was obtained first and the seasonal diurnal cycles were calculated by averaging the monthly diurnal cycles of the months of each season, where winter includes December, January and February, spring from March to May, summer from June to August, and autumn from September to November, respectively. The annual and seasonal mean diurnal cycles over Spain were obtained from the average of the cycles of all the stations. The time is 
always expressed in Coordinated Universal Time (UTC) and not in True Solar Time, but it should be noted that the Greenwich meridian passes over Spain, and the maximum correction due to the longitude of the stations is only 34 minutes.

The annual and seasonal diurnal cycles obtained are presented in the Results section, together with a harmonic analysis. Finally, the Discussion section shows an attempt to explain in a qualitative way the shape of the diurnal cycle on the basis of the factors that cause condensation, evaporation, and transport of water vapor.

\section{Results}

To put the diurnal cycle into context, firstly the annual and seasonal mean values of PWV for each station are discussed briefly. The annual mean ranges between $15.76 \mathrm{~mm}$ at Villafranca and $21.37 \mathrm{~mm}$ at Valencia, with the mean of all stations being 19.55 $\mathrm{mm}$. The lowest values of the annual mean of PWV are registered at the inland stations and the highest ones at the stations on the Mediterranean coast. With respect to the stations on the Atlantic coast, the two in the north (Coruña and Santander) register values similar to the lowest values of the stations on the Mediterranean coast, but the one located in the south (San Fernando) registers a lower value. As to the seasonal behavior, winter shows the lowest values and summer the highest, with a mean value $(26.01 \mathrm{~mm})$ that is about twice the winter value $(13.28 \mathrm{~mm})$. Similar summer-winter doubling differences are noticed for individual stations, ranging in summer between $20.31 \mathrm{~mm}$ at Cáceres and $30.06 \mathrm{~mm}$ at Valencia, and in winter between 10.78 $\mathrm{mm}$ at Villafranca and $15.02 \mathrm{~mm}$ at Coruña. Spring and autumn have values that are intermediate between winter and summer, with spring being more similar to winter and autumn more similar to summer. The stations situated inland register the lowest values in all seasons, whereas the highest values are registered at the stations on the Atlantic coast in winter and at those on the Mediterranean coast and at Santander (Atlantic coast) in the summer.

\subsection{Annual diurnal cycle}

According with the abovementioned procedure, Fig. 2 shows the annual average of the diurnal cycle for each station. One observed characteristic is that there is more dispersal in the PWV data among stations during daytime than during night. This result suggests that the mechanisms changing the PWV are more influenced by local effects during daytime than during night. The minimum value of PWV is reached approximately at the same time at most stations (around 0430-0530 UTC), whereas the maximum is reached in the second half of the day, but with a larger dispersion in its occurrence, varying from 1130 UTC at San Fernando to 2030 UTC at Alicante or Valencia. At most of the stations it is reached between 1730 and 2030 UTC. Only in the three most western stations (Coruña, Cáceres and San Fernando) the maximum is reached earlier.

The three stations on the Atlantic coast show a quite different diurnal cycle. However, the stations on the Mediterranean coast show cycles more similar to each other. The shape of the cycle at the inland stations is more similar to the one of Coruña station on the Atlantic coast.

The sub-daily variability (the difference between the maximum and the minimum value of the deviation from the mean) ranges between $0.41 \mathrm{~mm}$ at Villafranca, and $1.35 \mathrm{~mm}$ at Almería and Roquetes (Table I). The highest values are found at the stations on the Mediterranean coast, ranging between 0.99 and $1.35 \mathrm{~mm}$, whereas the lowest values are found at the inland stations, ranging between 0.41 and $0.58 \mathrm{~mm}$. The sub-daily variability relative to the annual mean value of PWV ranges between $6.7 \%$ at Almería and $2.6 \%$ at Villafranca. The highest values always take place at all the stations on the Mediterranean coast.

The diurnal mean cycle, obtained by averaging the cycles of all stations, has a sub-daily variability of $0.71 \mathrm{~mm}$. It decreases during the night to a minimum value of the anomaly of $-0.32 \mathrm{~mm}$ at about 0500 UTC. Thereafter, the PWV increases slowly until it reaches its maximum value of $0.39 \mathrm{~mm}$ at about 1830 UTC. Finally, the PWV decreases more quickly until it reaches again the nightly minimum. The shape of the mean annual diurnal cycle resembles an asymmetric sinusoid, with the descending branch shorter and more pronounced than the ascending one (Fig. 3). The height of the maximum is slightly greater than the depth of the minimum.

\subsection{Seasonal diurnal cycle}

From a visual comparison of the graphs of the seasonal averaged diurnal cycles (Fig. 2) it is noticed that the cycle is clearly stronger in summer than in any other season. In general, the maximum sub-daily variability occurs in summer. Only at inland stations it is larger in autumn (Cáceres) or spring (Villafranca). The lowest values of the sub-daily variability occur in winter; also the differences between stations are the lowest in winter, while in summer there is a larger dispersal (Table II). In spring the sub-daily variability is larger or slightly lower than in winter, except at Coruña, where it is reduced more than half of its winter value. In autumn, the sub-daily variability has values between the spring and the summer, except at Santander and at inland stations. The sub-daily variability ranges in summer from $0.62 \mathrm{~mm}$ at Villafranca to $3.19 \mathrm{~mm}$ at Valencia, with the lowest values at inland stations and the highest ones at the stations on the Mediterranean coast and at Santander; whereas in winter it ranges from $0.61 \mathrm{~mm}$ at San Fernando to $1.07 \mathrm{~mm}$ at Almería; in spring from $0.45 \mathrm{~mm}$ at Coruña to $1.15 \mathrm{~mm}$ at Valencia, with the lowest values at the western stations; and in autumn from $0.72 \mathrm{~mm}$ at Villafranca to $1.77 \mathrm{~m}$ at Almería, with the highest values at the stations on the Mediterranean coast.

Concerning the shape of the cycle, in winter it is quite similar at all locations despite their geographical situation. The dispersal increases in spring, and even more in autumn. In summer, local effects are felt strongly, making the diurnal cycle quite different among stations. At least two distinctly different cycles appear at all stations, one in winter and another in summer. At some stations spring and autumn show transitional intermediate shapes between winter and summer, like at the stations on the Mediterranean coast, whereas at others, they are similar to the winter cycle (San Fernando) or to the summer one (Coruña).

Averaging the cycles of all stations (Fig. 4), summer is characterized by the highest sub-daily variability (1.34 mm), describing a curve with a wide minimum between 0630 UTC and 0930 UTC and a sharper maximum around 2130 UTC, with the slope of the decreasing phase greater than the increasing phase. In winter the cycle is weaker, the sub-daily variability is only $0.69 \mathrm{~mm}$, and 
the maximum is reached around 1030 UTC. The lowest sub-daily variability is found in spring $(0.66 \mathrm{~mm})$, slightly lower than in winter. In that season the increase of PWV starts later than in winter, the PWV decreases slightly from midnight to 1130 UTC, thereafter it increases until evening, where a wide maximum takes place (1730 - 2030 UTC), and finally it decreases pronouncedly until midnight. Autumn have a more similar behavior to summer, but with a phase lag, minimum and maximum values take place earlier in autumn than in summer, and a lower sub-daily variability $(1.06 \mathrm{~mm})$, almost half way between winter and summer.

According to Wang et al. (2007), the mean diurnal cycle for the European region, based on an average of 110 GPS stations distributed over the entire continent, is strongest in summer, with a sub-daily variability of $\sim 1.2 \mathrm{~mm}$, weaker in winter and autumn, and practically negligible in spring. The PWV maximum is reached at 1100 Local Solar Time (LST) in winter, around 1600-1800 LST in autumn, and between 2000 and 2200 LST in summer. The results obtained in the present study are in good agreement with the results of Wang et al. (2007) in summer, autumn and winter, both in the shape of the cycle and the in time of the maximum, but with slightly higher amplitude values in Spain than in the rest of Europe in summer and autumn. In spring, the mean cycle for Spain is stronger than for the Europe region.

\subsection{Harmonic analysis}

The PWV annual diurnal cycle at each GPS station was subjected to a harmonic analysis. The amplitude (half of the peak-topeak amplitude), phase (UTC time at the maximum) and variance of the four first harmonics with periods 24, 12, 8 and 6 hours are represented in Table III. The 24-h period harmonic $\left(\mathrm{S}_{1}\right)$ explains in average over $85 \%$ of the sub-daily variance, whereas the 12-h period harmonic $\left(S_{2}\right)$ explains over $12 \%$, the 8-h period one $\left(S_{3}\right)$ only $1 \%$, and the 6 -h period $\left(S_{4}\right)$ is negligible. $S_{1}$ is the dominant harmonic for all the stations. The variance explained by this harmonic ranges from $74 \%$ at Coruña to $96 \%$ at Cáceres. $\mathrm{S}_{2}$ is the second dominant harmonic for all the stations, with an explained variance ranging from $1.5 \%$ at Cáceres to $22.5 \%$ at Coruña. Thus, $S_{1}$ and $S_{2}$ together explain most of the variance $(97 \%)$. Only at half of the stations the variance explained by $S_{3}$ is higher than $1 \%$, being its maximum value $3.8 \%$ at Villafranca, while $\mathrm{S}_{4}$ explains more than $1 \%$ only at Coruña $(1.4 \%)$.

The amplitude of $S_{1}$ is more than twice the amplitude of $S_{2}$, and at some stations even much more, whereas the amplitudes of $S_{3}$ and $S_{4}$ are negligible. The dispersal of the phases of $S_{2}$ is higher than that of $S_{1}$. The phase of $S_{1}$ ranges from 0930 UTC at San Fernando to 2030 UTC at Valencia, although at most of the stations it ranges from 1700 UTC to 2030 UTC. In contrast, the phase of $\mathrm{S}_{2}$ is approximately between 0330 and 1030 UTC.

These results agree with those obtained by Dai et al. (2002). They decomposed the diurnal cycle of PWV of 54 stations over North America into simple harmonics (with periods of 24, 12, 8 and $6 \mathrm{~h}$ ) and found that the diurnal cycle was well represented only with the first two harmonics. The $24-h$ period explained more than $50 \%$ of the variance, while the $12-h$ period explained less than $25 \%$. Both together explained more than $80 \%$ of the variance for most of the stations.

Also the seasonal diurnal cycles were subjected to a harmonic analysis (Fig. 4). Table IV contains the parameters of this analysis for the average cycles of all stations. Together $S_{1}, S_{2}$ and $S_{3}$ explain approximately the same variance for every season $(96-98 \%)$, but not always at the same rate. $S_{1}$ is always by far the most dominant harmonic, but it explains a little more variance in summer and autumn (92-96\%) than in winter and spring (83-86\%). The amplitude of $S_{1}$ is in summer more than twice the winter or spring, and its phase is at noon in winter, in the afternoon in autumn and in the evening in spring and summer. $S_{2}$ is more significant in spring, explaining $14 \%$ of the variance, while in the other seasons it explains between $1 \%$ and $4 \%$. The variance explained by $S_{3}$ is only significant in winter $(7 \%)$, and $S_{4}$ is always negligible. However, there is a great dispersal between stations in the variance explained by each harmonic for each season.

\section{Discussion}

The mechanisms producing variations in the PWV can be classified into three groups: large scale changes of the air mass, evaporation and condensation within the air mass, and wet and dry advections (local winds). The variations due to the large scale changes of the synoptical situation do not follow a diurnal cycle pattern, so that when averaging over a large number of days, they are compensated, with only those variations related to the diurnal cycle of solar radiation remaining (Wu et al., 2003). The latter is one of the main factors that determines the diurnal variations of PWV, as well as temperature, evapotranspiration (Dai et al., 1999b), local wind circulation (Dai and Deser, 1999), condensation and precipitation (Dai et al., 1999a; Dai, 2001), or vertical air motion (Dai et al., 1999a). The diurnal cycle of the PWV is determined by the sum of the contributions of each of these factors.

In this section some of the features of the PWV diurnal cycle mainly on the basis of the air temperature, the transport of moisture by local winds, and the turbulent mixture in the vertical are presented in a qualitative way.

Temperature should be perhaps the most important factor. Diurnal warming drives evaporation, which increases the PWV. Moreover, according to Clausisus-Clapeyron's equation the higher the temperature the more water vapor the air can contain before condensation takes place. During the night, the cooling causes a decrease of the PWV by condensation.

Another important factor is the wind. Wind enables the evaporation in the lower atmospheric layers near the ground and acts like a conveyor belt of moisture. The diurnal variability of the wind, obtained by subtracting the mean component due to the synoptical situation, is determined by the movement of the sun and by local geographical effects. Due to changes in solar elevation, the wind speed gets stronger during daytime and weakens down during night. Wind direction is also influenced by solar position, with the wind tending to blow towards the point of the vertical of the sun due to the thermal depression that it generates, i.e., westerly wind in the morning veering to easterly wind in the afternoon. Breezes (both sea and mountain) are clear examples of local wind regimes. Its mechanism is well known. It is the result of differential warming between land and sea or between valley and mountain that establishes a gradient of pressure that generates the wind. During daytime sea breezes 
carry moisture inland. During the night the higher cooling of the land causes the breeze regime to reverse, blowing from land to sea (land breeze). The land breeze advects air previously advected inland by the sea breeze towards the coast, which after having undergone cooling and condensation, is now drier. The appearance and onset time of the breezes and the vertical growth of the affected layer also depend also on the general synoptical situation (Bastin et al., 2007). The diurnal variation of PWV seems to be strongly conditioned by local thermal circulations generated by the topography (Li et al., 2008). The phase lag between stations in the PWV diurnal cycle can be explained by this factor on the basis of moisture transport.

Vertical motion transports moisture from lower layers to upper layers, disperses PWV and enhances evaporation. Water vapor enters the atmosphere from the earth's surface by evaporation and is accumulated in the layer closest to the ground. When the sun rises, the diurnal warming triggers the turbulent and the vertical mixing. The thickness of the mixed layer increases with the intensity of the incident solar radiation. When updrafts are generated around noon, PWV increases, although the specific humidity next the ground decreases (Wu et al., 2003). The variations of PWV above the mixed layer can be attributed to advections of moisture by local currents induced by differential warming (Kimura et al., 1997). During night there is no thermal turbulence and cooling at night increases stability and stratification in the lower layers of the atmosphere.

Fig. 5 shows the annual mean diurnal cycle of temperature, which is almost the same at all stations. It can be observed that at most stations the minima of PWV and temperature cycles occur nearly in one hour interval. However, the same does not happen with the maxima, where there is a longer phase lag (Li et al., 2008). Only at Cáceres and Coruña the maxima of both cycles are approximately in phase, whereas at the stations on the Mediterranean coast, as well as at Santander, the maximum PWV is reached between four to six hours later than the temperature one. San Fernando is a special case; it is the only site where the maximum PWV occurs before the temperature maximum. It is clear that the diurnal cycle of temperature alone would not be a proxy for PWV cycle, especially during daytime.

At coastal stations the diurnal cycle of PWV could be greatly influenced by the advection of moisture by sea breezes, causing the PWV to continue to increase even after the air temperature has already begun to decrease. For example, at a typical station of the Mediterranean coast, such as Valencia, it is seen how the sea breeze regime is established every season. Nevertheless, the see breeze regime sets in earlier, is stronger and lasts longer in summer than in winter, because of the higher insolation in this season (Fig. 6). Comparing the seasonal diurnal cycles of PWV (Fig. 2) and the relative frequency of the wind direction (Fig. 6 ), it is observed that the maximum PWV is reached approximately at the same time the regime breeze turns from sea to land for all seasons. In general, the phase lag is much shorter in winter than in summer, when the see breeze is stronger. These observations confirm that at this station the breeze regime is the main factor responsible for the phase lag between PWV and temperature cycles during daytime. Also the relative minimum, which occurs at Valencia just after noon coinciding with the temperature maximum, can be attributed to the breeze regime. This can be seen clearly in summer. Just after sunrise, a decrease in PWV occurs approximately at the onset time of the sea breeze. At this moment the land is hotter than the sea and the warm air above ground, which contains evaporated moisture from the surface, rises and is replaced by colder and drier air originating from the sea. In the afternoon, as the sea warms, it provides a continuous source of moisture to the air above it. Thus, the sea breeze becomes an important conveyor of moisture towards inland, increasing the PWV until the sea breeze finally weakens. This minimum does not appear at all stations, because PWV also depends on the amount of moisture available in the soil.

Although there is a breeze regime at Coruña station (on the Atlantic coast), it is not as strong as the breeze effect at the stations on the Mediterranean coast. As a result, it transports less moisture due to the lower temperature of the Atlantic Ocean than the Mediterranean Sea, such that in the annual average PWV and temperature cycles are in phase at this station. However, Santander (also on the Atlantic coast) shows a behavior more similar to any of the Mediterranean stations than to Coruña. This difference could arise from its location at the foot of the Cantábrica mountain range. This range $(480 \mathrm{~km}$ long, $100 \mathrm{~km}$ wide and with a highest altitude of 2,648 $\mathrm{m}$ ) extends parallel to the coast line. In this area, the sea breezes are enhanced by the valley breezes generated by the presence of the mountain range (Sasaki and Kiruma, 2001; Ohtani, 2001), resulting in a more intensive breeze (Fig. 7).

At the inland stations, the annual diurnal cycles of PWV and temperature seem to be more in phase, because there is not a dominant diurnal wind regime where the PWV has changed substantially. However, if we study the seasonal mean cycles, a phase lag is noticeable, but with opposite sign in winter and summer. In winter the PWV maximum is reached earlier in the day than the temperature maximum, whereas in summer it occurs the other way around. The reason why the maximum of PWV is reached before the maximum temperature in winter could be explained by the cessation of vertical mixing. During winter, the stratification of the atmosphere is greater, typical in the presence of a subsidence inversion. This inversion acts like a cap, inhibiting the vertical transport and limiting turbulent mixing. Thus, even as the temperature continues to rise, evaporation stops.

At San Fernando, even in summer, the maximum PWV is reached early in the day, around noon. Due to its geographical location on the coast, the sea breeze is already well established at noon (Fig. 8). In contrast to the other stations on the coast, where the sea breeze should continue to provide moisture until late evening, this persistence does not seem to occur here. The explanation for this peculiarity could lie in the proximity of the station to the strait of Gibraltar, between the Atlantic and the Mediterranean. During the night the wind blows from land to sea, but the air mass over the land can be influenced by the Mediterranean Sea on the other side of the strait, so that it is warm and wet. After the sea breeze is established in the morning, the wind turns from east to west (from the Atlantic), which is colder than the Mediterranean, resulting in a replacement of the air mass over the station other dryer air. When the sea breeze begins to weaken in the late evening, the easterly winds transport moisture and the PWV increases, even when the temperature is decreasing. However, additional analysis is needed to understand this more complicated situation.

No clear correlation between the daily cycle of precipitation and PWV has been found. It is true that the diurnal heating (related to the content of PWV) is a factor to trigger convection. However, at Spain's latitudes convective precipitation is not the most 
important, but frontal precipitation determined by the synoptical situation, which does not follow a daily cycle. Only Valencia in autumn shows a significant increase in the precipitation in the second half of the day when the PWV is higher (Fig. 9), and the other way round at San Fernando in autumn and spring, where there is more amount of precipitation in the first half of the day (Fig. 10). This also agrees with the fact that the maximum of PWV takes place at that station before noon. Also at Santander in summer a minimum of precipitation has been found around noon, coinciding with the minimum of PWV.

PWV diurnal cycle can be influenced by cloudiness, so that, we divided up the data into two groups, one corresponding to the days with the highest temperature amplitude (mostly sunny days), and the other with the lowest temperature amplitude (mostly cloudy days). We have analyzed separately both data groups for each season. As a general rule we have found that at coastal locations the higher the temperature amplitude, the higher the PWV amplitude in all seasons except in winter. At inland locations, the higher the temperature amplitude, the lower the PWV amplitude in all seasons. The thermal oscillation plays a major role in the PWV diurnal amplitude when there is an unlimited source of water vapor and the intensity of the solar radiation is high. However, these conditions do not occur in winter and at inland locations. In those cases, other factors like could be the airmass type or the atmospheric instability are more determining, resulting that days with lower thermal oscillation present higher PWV variation.

Among the abovementioned factors, temperature and local winds present a 24 -hour diurnal cycle. Thus, the $S_{1}$ harmonic must be mainly produced by the addition of their contributions. The dispersal in the phase of this harmonic indicates the different contribution of both factors in each station. Local winds are weaker in winter than in summer, so in winter $\mathrm{S}_{1}$ is more similar to the temperature diurnal cycle.

Another effect influencing the PWV diurnal cycle at the stations located in urban areas is the anthropogenic change of the surface. In urban areas, evaporation is limited by the lack of water sources during summer. During winter, water vapor is produced by combustion. Moreover, the urban heat island can establish urban breeze similar to sea breeze (Champollion et al., 2009).

\section{Conclusions}

The knowledge of the diurnal cycle of PWV can be applied to a better modeling of the water vapor attenuation of the direct solar radiation and subsequently improve atmospheric correction of the satellite images. The PWV temporal variation also provides a test bed for many aspects of the physical parameterizations in numerical weather models and subsequently improves convective activity forecasting. The GPS receivers have proven to be an appropriate technique to determine the PWV diurnal cycle. The annual and seasonal diurnal cycles of PWV have been studied at ten stations over Spain using the data provided by the GPS receivers. In general, the minimum value of PWV is reached close to dawn, approximately at the same time at all the stations, whereas the maximum is reached in the afternoon or in the evening. Both the annual and the seasonal diurnal cycles at the different stations are more similar each other during the night than during the afternoon. The mechanisms changing the PWV are influenced more by local effects during daytime than during night. The annual sub-daily variability ranges from 0.41 to $1.35 \mathrm{~mm}(3-7 \%)$. The highest values are recorded at the stations on the Mediterranean coast, more than twice the values of the inland stations. Also the amplitude of the cycle is higher in summer than in winter, often by factors two or three times at the stations on the Mediterranean coast. The diurnal cycle in winter is quite similar at all locations, whereas in summer it is quite different. Summer is characterized by the highest sub-daily variability $(1.34 \mathrm{~mm})$ and the PWV maximum around 2130 UTC. In winter and spring the sub-daily variability is the lowest $(0.69$ and $0.66 \mathrm{~mm}$ respectively), but the maximum is reached around 1030 UTC in winter and between 1730 UTC and 2030 UTC in spring. Autumn have a more similar behavior to summer, but with a phase lag and a lower sub-daily variability $(1.06 \mathrm{~mm})$. Harmonic analysis shows that only the first two harmonics with period of 24 , and 12 hours have a significant contribution. The first one is dominant, explaining $85 \%$ of the variance, whereas the second one explains $12 \%$. The diurnal and semi-diurnal harmonics together can explain $97 \%$ of the variance. The diurnal harmonic explains a little more variance in summer and autumn than in winter and spring. Its amplitude is in summer more than twice the winter or spring, and its phase is at noon in winter, in the afternoon in autumn and in the evening in spring and summer. The semi-diurnal harmonic explains more variance in spring than in any other season, whereas the 8-hour period harmonic is only significant in winter. Although a more detailed analysis is needed to explain all the features at each station, as a result of the influence of local effects, the main features of the PWV diurnal cycle in the different locations can be explained in a general and qualitative way on the basis of the air temperature diurnal cycle, the transport of moisture by local winds (breezes), and the turbulent vertical mixing. Precipitation does not follow a significant diurnal cycle. Latent heat fluxes data from numerical models could enhance the affirmations about the relation between temperature, state of the boundary layer and PWV variations, because evaporation depends on the latent heat flux which depends not only on temperature. The PWV diurnal cycle can exhibit a climatic variation related to large scale oscillation like NAO or a drift due to the increase of the mean temperature by global warming, but longer series are needed to study such correlations. Besides the sub-daily variability, described in this paper, PWV shows oscillations of longer period, such as the annual cycle, and even it could present a 7-day period cycle due to human activities.

\section{Acknowledgements}

The GOA-UVA is funded by CICYT projects CGL2008-05939-C03-01/CLI and CGL2009-05693-C03/CLI, and under the project of Junta de Castilla y León Excellence Program. One of us (NL) was supported by the U.S. Department of Energy under Contract DE-AC06-76RLO 1830. Pacific Northwest National Laboratory is operated for the U.S. DOE by Battelle Memorial Institute. 
Bastin S, Champollion C, Bock O, Drobinski P, Masson F. 2007. Diurnal Cycle of Water Vapor as Documented by a Dense GPS Network in a Coastal Area during ESCOMPTE IOP2. J. Appl. Meteor. Climatol., 46, 167-182.

Bevis M, Businger S, Herring TA, Rocken C, Anthes RA, Ware RH. 1992. GPS Meteorology: Remote Sensing of Atmospheric Water Vapor using the Global Positioning System. J. Geophys. R., 97, 15787-15801.

Bevis M, Businger S, Chiswell S, Herring TA, Anthes RA, Rocken C, Ware RH. 1994. GPS Meteorology: Mapping Zenith Wet Delays onto Precipitable Water. J. App. Meteorology, 33, 379-386.

Bokoye Al, Royer A, O'Neill NT, Cliché P, McArthur LJB, Teillet PM, Fedosejevs G, Thériault JM. 2003. Multisensor analysis of integrated atmospheric water vapor over Canada and Alaska. J. Geophys. Res., 108(D15), 4480, DOI:10.1029/2002JD002721.

Brunner FK, Gu M. 1991. An improved model for the dual frequency ionospheric correction of GPS observations. Manusc. Geod., 16, 205-214, 1991.

Champollion C, Drobinski P, Haeffelin M, Bock O, Tarniewicz J, Bouin MN, Vautard R. 2009. Water vapour variability induced by urban/rural surface heterogeneities during convective conditions. Q. J. R. Meteorol. Soc. 135, 1266-1276, 2009. DOI:10.1002/qj.446

Dai A, Deser C. 1999. Diurnal and semidiurnal variations in global surface wind and divergence fields. J. Geophys. Res., 104, $31,109-31,125$.

Dai A, Giorgi F, Trenberth KE. 1999a. Observed and model-simulated precipitation diurnal cycle over the contiguous United States. J. Geophys. Res., 104, 6377-6402.

Dai A, Trenberth KE, Karl TR. 1999b. Effects of clouds, soil moisture, precipitation and water vapor on diurnal temperature range. J. Clim., 12, 2451-2473.

Dai A. 2001. Global precipitation and thunderstorm frequencies, II, Diurnal variations. J. Clim., 14, 1112-1128.

Dai. A, Wang J, Ware RH, van Hove T. 2002. Diurnal variation in water vapor over North America and its implications for sampling errors in radiosonde humidity. J. Geophys. Res., 107(D10), 4090, DOI:10.1029/2001JD000642.

Davis JL, Herring TA, Shapiro II, Rogers AE, Elgered G. 1985. Geodesy by radio interferometry: Effects of atmospheric modeling errors on estimates of baseline length. Radio Sci., 20, 1593-1607.

De Haan S. 2006. National/regional operational procedures of GPS water vapor networks and agreed international procedures, WMO - World Meteorological Organization. Instruments and Observing Methods, Report No. 92.

Duan J, Bevis M, Fang P, Bock Y, Chiswell S, Businger S, Rocken C, Solheim F, van Hove T, Ware R, McClusky S, Herring TA, King RW. 1996. GPS Meteorology: Direct Estimation of the Absolute Value of Precipitable Water. J. Applied Meteorology, 35, 830-838, 1996.

Elgered G, Davis JL, Herring TA, Shapiro II. 1991. Geodesy by radio interferometry: Water vapor radiometry for estimation of the wet delay. J. Geophys. Res., 96, 6541-6555, 1991.

Hagemann S, Bengtsson L, Gendt G. 2003. On the determination of atmospheric water vapor from GPS measurements. J. Geophys. Res., 108(D21), 4678.

Herring T, Davis JL, Shapiro II. 1990. Geodesy by radio interferometry: The application of Kalman filtering to the analysis of very long baseline interferometry data. J. Geophys. Res., 95, 12,561-12,581, 1990.

Jakobson E, Ohvril H, Elgered G. 2009. Diurnal variability of precipitable water in the Baltic region, impact on transmittance of the direct solar radiation. Boreal Env. Res., 14: 45-55.

Kimura F, Tanikawa R, Yoshizaki M. 1997. Diurnal variation of precipitable water in clear days over the northern mountains in Kanto plain. Tenki, 44, 799-807.

Li G, Kimura F, Sato T, Huang D. 2008. A composite analysis of diurnal cycle of GPS precipitable water vapor in central Japan during Calm Summer Days. Theor. Appl. Climatol., 92, 15-29, DOI:10.1007/s00704-006-0293-x.

Morland J, Collaud Coen M, Hocke K, Jeannet P, Mätzler C. 2009. Tropospheric water vapour above Switzerland over the last 12 years. Atmos. Chem. Phys., 9, 5975-5988, 2009.

Ohtani R, Naito I. 2000. Comparisons of GPS-derived precipitable water vapors with radiosonde observations in Japan. J. Geophys. Res., 105(D22), 26,917-26,929.

Ohtani R. 2001. Detection of water vapor variations driven by thermally induced local circulations using the Japanese continuous GPS array. Geophys. Res. Lett., 28, 151-154. 
Ortiz de Galisteo JP, Toledano C, Cachorro V, Torres B. 2010. Improvement in PWV estimation from GPS due to the absolute calibration of antenna phase center variation. GPS Solut., 14, 389-395, 2010. DOI:10.1007/s10291-010-0163-y.

Ray RD, Ponte RM. 2003. Barometric tides from ECMWF operational analyses. Ann. Geophys., 21, 1897-1910, 2003. DOI:10.5194/angeo-21-1897-2003.

Rocken C, Ware R, Van Hove T, Solheim F, Alber C, Johnson J. 1993. Sensing atmospheric water vapor with the global positioning system. Geophysical R. Letters, vol. 20, pag. 2631-2634, 1993.

Saastamoinen J. 1972. Atmospheric correction for the troposphere and stratosphere in radio ranging of satellites, in The Use of Artificial Satellites for Geodesy. Geophys. Monogr. Ser., vol. 15, edited by S. W. Henriksen, et al., pp. 247-251, AGU, Washington, D.C., 1972.

Sasaki T, Kimura F. 2001. Diurnal variation of water vapor content over the Kanto area during clear summer days observed through GPS precipitable water. Tenki, 48, 65-74.

Schneider M, Romero PM, Hase F, Blumenstock T, Cuevas E, Ramos R. 2009. Quality assessment of Izaña's upper-air water vapor measurement techniques: FTIR, Cimel, MFRSR, GPS, and Vaisala RS92. Atmos. Meas. Tech. Discuss., 2, 1625-1662, 2009.

Spilker JJ. 1980. GPS signal structure and performance characteristics, in Global Positioning System, vol. 1, The Institute of Navigation, Washington, D.C., 1980.

Tralli DM, Lichten SM. 1990. Stochastic estimation of tropospheric path delays in global positioning system geodetic measurements. Bull. Geod., 64, 127-159, 1990.

Wang J, Zhang L, Dai A. 2005. Global estimates of water-vapor-weighted mean temperature of the atmosphere for GPS applications. J. Geophys. Res., 110, D21101, DOI:10.1029/2005JD006215.

Wang J, Zhang L, Dai A, van Hove T, van Baelen J. 2007. A near-global, 2-hourly data set of atmospheric precipitable water from ground-based GPS measurements. J. Geophys. Res., 112, D11107, DOI:10.1029/2006JD007529.

Wu P, Hamada J, Mori S, Tauhid YI, Yamanaka MD, Kimura F. 2003. Diurnal variation of precipitable water over a mountainous area of Sumatra Island. J. Appl. Meteor., 42, 1107-1115.

\section{TABLES}

\begin{tabular}{lccrcc}
\hline Station & Lat. & Lon. & Elev. & V & $\%$ \\
\hline Alicante & $38^{\circ} 20^{\prime}$ & $0^{\circ} 29^{\prime}$ & 10 & 1.08 & 5.1 \\
Almería & $36^{\circ} 51^{\prime}$ & $2^{\circ} 28^{\prime}$ & 77 & 1.35 & 6.7 \\
Cáceres & $39^{\circ} 29^{\prime}$ & $6^{\circ} 21^{\prime}$ & 384 & 0.58 & 3.5 \\
Coruña & $43^{\circ} 22^{\prime}$ & $8^{\circ} 24^{\prime}$ & 12 & 0.68 & 3.4 \\
Creus & $42^{\circ} 19^{\prime}$ & $-3^{\circ} 19^{\prime}$ & 84 & 0.99 & 4.9 \\
Roquetes & $40^{\circ} 49^{\prime}$ & $-0^{\circ} 30^{\prime}$ & 58 & 1.35 & 6.4 \\
S. Fernando & $36^{\circ} 28^{\prime}$ & $6^{\circ} 12^{\prime}$ & 40 & 0.61 & 3.2 \\
Santander & $43^{\circ} 28^{\prime}$ & $3^{\circ} 48^{\prime}$ & 48 & 0.94 & 4.6 \\
Valencia & $39^{\circ} 29^{\prime}$ & $0^{\circ} 20^{\prime}$ & 28 & 1.33 & 6.2 \\
Villafranca & $40^{\circ} 27^{\prime}$ & $3^{\circ} 57^{\prime}$ & 596 & 0.41 & 2.6 \\
\hline
\end{tabular}

Table I. GPS sites. (Lat.) Latitude (North), (Lon.) Longitude (positive West, negative East), (Elev.) Elevation in meters above sea level, (V) sub-daily variability in absolute value, and (\%) relative to the mean PWV.

\begin{tabular}{l|c|c|c|c}
\hline Station & Win. & Spr. & Sum. & Aut. \\
\hline Alicante & 0.76 & 0.95 & 2.16 & 1.47 \\
Almería & 1.07 & 1.00 & 2.41 & 1.77 \\
Cáceres & 0.77 & 0.70 & 0.94 & 1.08
\end{tabular}




\begin{tabular}{l|l|l|l|l} 
Coruña & 0.88 & 0.45 & 1.23 & 0.89 \\
Creus & 0.81 & 0.71 & 1.89 & 1.06 \\
Roquetes & 0.69 & 0.95 & 3.16 & 1.66 \\
S. Fernando & 0.61 & 0.51 & 1.55 & 0.90 \\
Santander & 0.84 & 1.06 & 2.38 & 0.74 \\
Valencia & 0.63 & 1.15 & 3.19 & 1.59 \\
Villafranca & 0.64 & 0.99 & 0.62 & 0.72 \\
\hline
\end{tabular}

Table II. Seasonal mean sub-daily variability (mm).

\begin{tabular}{l|ccc|ccc|ccc|ccc|c|}
\hline & \multicolumn{3}{|c|}{ 24-h harmonic } & \multicolumn{3}{|c|}{$\mathbf{1 2 - h}$ harmonic } & \multicolumn{3}{|c|}{$\mathbf{8 - h}$ harmonic } & \multicolumn{3}{|c|}{$\mathbf{6 - h}$ harmonic } & \\
Station & $\mathbf{A}$ & $\mathbf{P h}$ & $\mathbf{V}$ & $\mathbf{A}$ & $\mathbf{P h}$ & $\mathbf{V}$ & $\mathbf{A}$ & $\mathbf{P h}$ & $\mathbf{V}$ & $\mathbf{A}$ & $\mathbf{P h}$ & $\mathbf{V}$ & $\mathbf{V ~ T}$ \\
\hline Alicante & 0.46 & 17.3 & 87.6 & 0.15 & 7.9 & 9.4 & 0.05 & 0.6 & 1.1 & 0.03 & 3.3 & 0.5 & 98.5 \\
Almería & 0.63 & 17.1 & 94.3 & 0.13 & 8.5 & 4.0 & 0.05 & 3.6 & 0.5 & 0.00 & 0.0 & 0.0 & 98.8 \\
Cáceres & 0.28 & 15.6 & 96.1 & 0.04 & 10.1 & 1.5 & 0.02 & 0.0 & 0.5 & 0.00 & 0.0 & 0.0 & 98.1 \\
Coruña & 0.23 & 14.3 & 74.0 & 0.12 & 3.7 & 21.5 & 0.00 & 0.0 & 0.0 & 0.03 & 2.9 & 1.4 & 97.0 \\
Creus & 0.40 & 17.0 & 84.1 & 0.15 & 5.6 & 11.7 & 0.07 & 0.7 & 2.3 & 0.02 & 3.2 & 0.3 & 98.5 \\
Roquetes & 0.67 & 17.2 & 95.8 & 0.12 & 3.8 & 2.9 & 0.03 & 7.0 & 0.2 & 0.00 & 0.0 & 0.0 & 98.9 \\
S. Fernando & 0.25 & 9.7 & 75.3 & 0.13 & 10.7 & 21.1 & 0.03 & 4.4 & 1.2 & 0.00 & 0.0 & 0.0 & 97.6 \\
Santander & 0.38 & 20.2 & 81.5 & 0.17 & 5.9 & 16.7 & 0.00 & 0.0 & 0.0 & 0.03 & 2.4 & 0.4 & 98.6 \\
Valencia & 0.56 & 20.4 & 82.8 & 0.24 & 7.8 & 14.6 & 0.06 & 1.4 & 1.1 & 0.04 & 3.2 & 0.3 & 98.8 \\
Villafranca & 0.16 & 18.6 & 76.3 & 0.08 & 5.5 & 16.9 & 0.04 & 1.7 & 3.8 & 0.00 & 0.0 & 0.0 & 97.0 \\
\hline MEAN & $\mathbf{0 . 4 0}$ & $\mathbf{1 6 . 7}$ & $\mathbf{8 4 . 8}$ & $\mathbf{0 . 1 3}$ & $\mathbf{7 . 0}$ & $\mathbf{1 2 . 0}$ & $\mathbf{0 . 0 3}$ & $\mathbf{2 . 0}$ & $\mathbf{1 . 1}$ & $\mathbf{0 . 0 1}$ & $\mathbf{1 . 5}$ & $\mathbf{0 . 3}$ & $\mathbf{9 7 . 9}$ \\
\hline
\end{tabular}

Table III. Harmonic analysis of the PWV annual diurnal cycle. (A) Amplitude (mm), (Ph) phase (UTC time at the maximum), (V) variance explained, and (VT) total variance explained by the four harmonics together.

\begin{tabular}{l|ccc|ccc|ccc|ccc|c|}
\hline & \multicolumn{2}{|c|}{ 24-h harmonic } & \multicolumn{2}{|c|}{ 12-h harmonic } & \multicolumn{3}{|c|}{ 8-h harmonic } & \multicolumn{3}{|c|}{ 6-h harmonic } & \multicolumn{1}{|c}{} \\
Season & A & Ph & V & A & Ph & V & A & Ph & V & A & Ph & V & V T \\
\hline Winter & 0.25 & 12.1 & 86.2 & 0.04 & 5.6 & 2.2 & 0.07 & 2.1 & 7.4 & 0.00 & 0.0 & 0.0 & 95.7 \\
Spring & 0.28 & 19.6 & 82.6 & 0.12 & 6.3 & 13.9 & 0.00 & 2.0 & 0.0 & 0.02 & 0.0 & 0.6 & 97.0 \\
Summer & 0.66 & 19.0 & 95.5 & 0.07 & 8.8 & 1.1 & 0.08 & 5.3 & 1.4 & 0.00 & 0.0 & 0.0 & 98.0 \\
Autumn & 0.46 & 16.2 & 92.3 & 0.10 & 6.8 & 4.1 & 0.06 & 0.8 & 1.8 & 0.00 & 0.0 & 0.0 & 98.2 \\
\hline
\end{tabular}

Table IV. Harmonic analysis of the PWV seasonal mean diurnal cycles (see Table III).

\section{FIGURES}




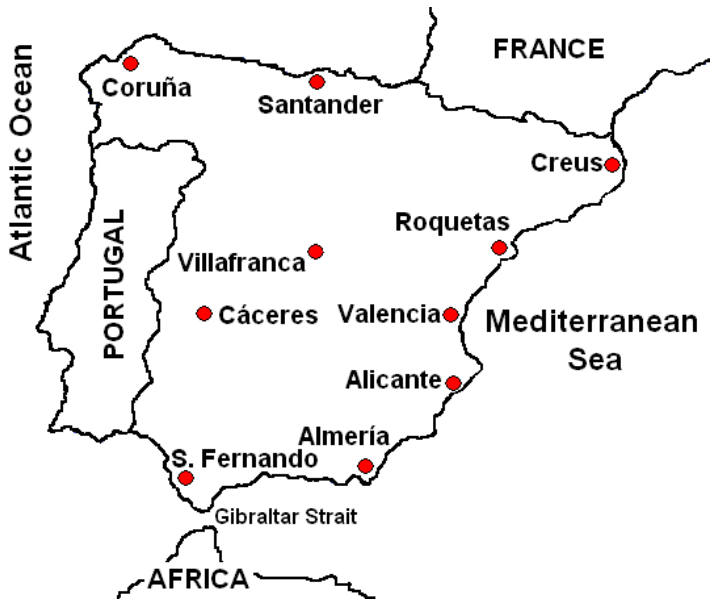

Fig. 1.- Location of the GPS ground receivers. 

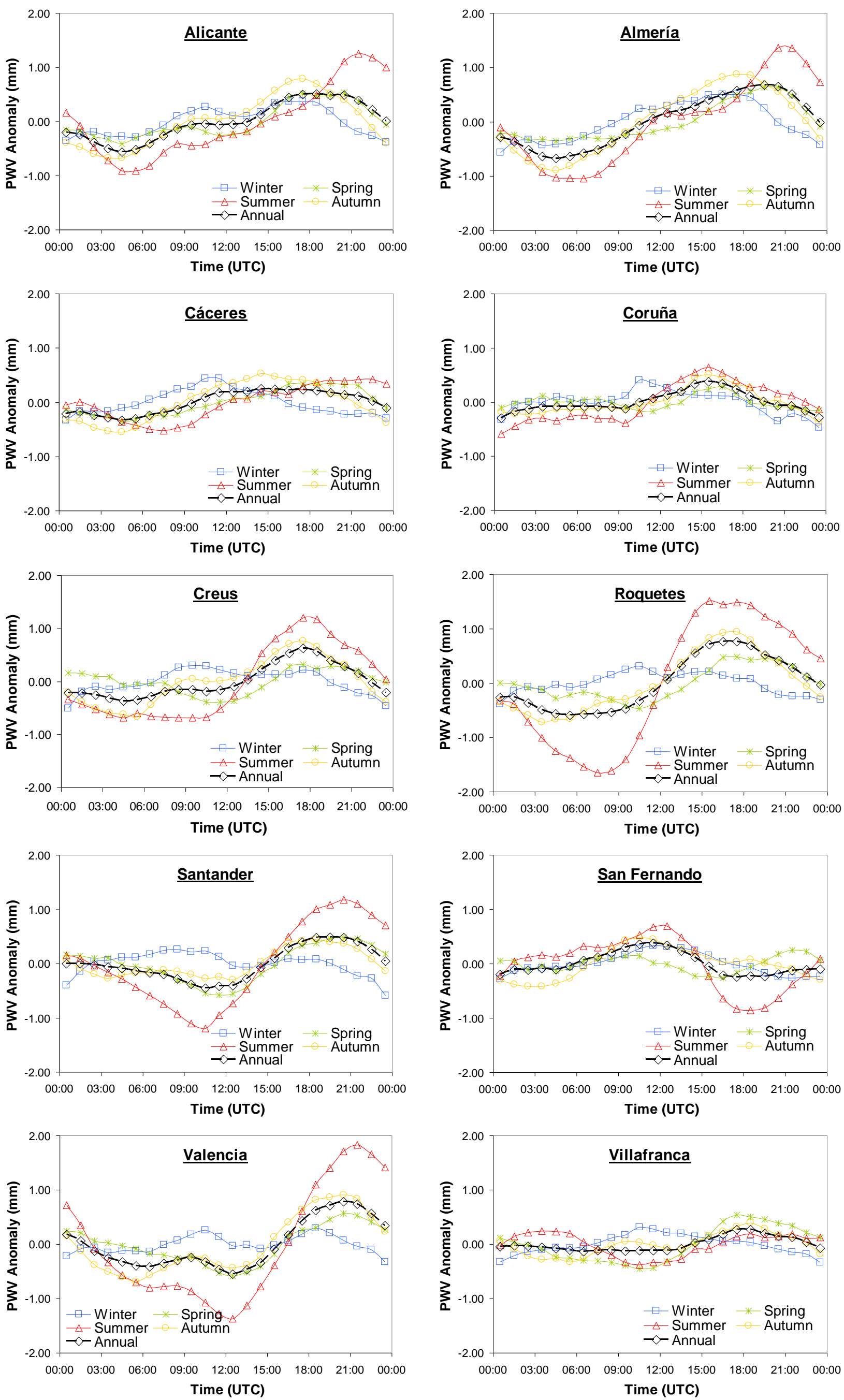

Fig. 2.- Annual and seasonal diurnal cycles for each station. 


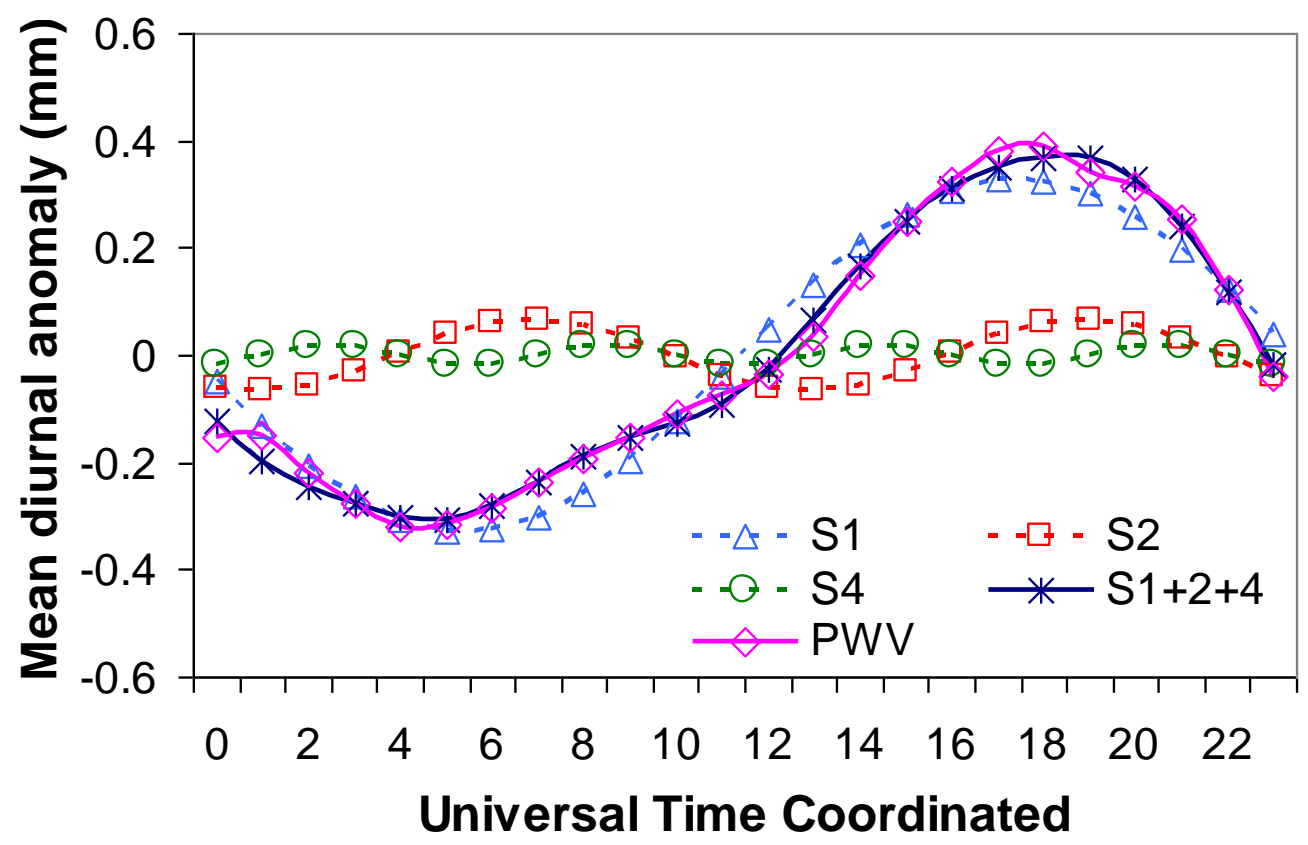

Fig. 3.- Annual mean diurnal cycle and harmonic analysis: $S_{1}, S_{2}, S_{3}$, and $S_{4}$ are the harmonic of $24,12,8$ and 6 -hour period. 

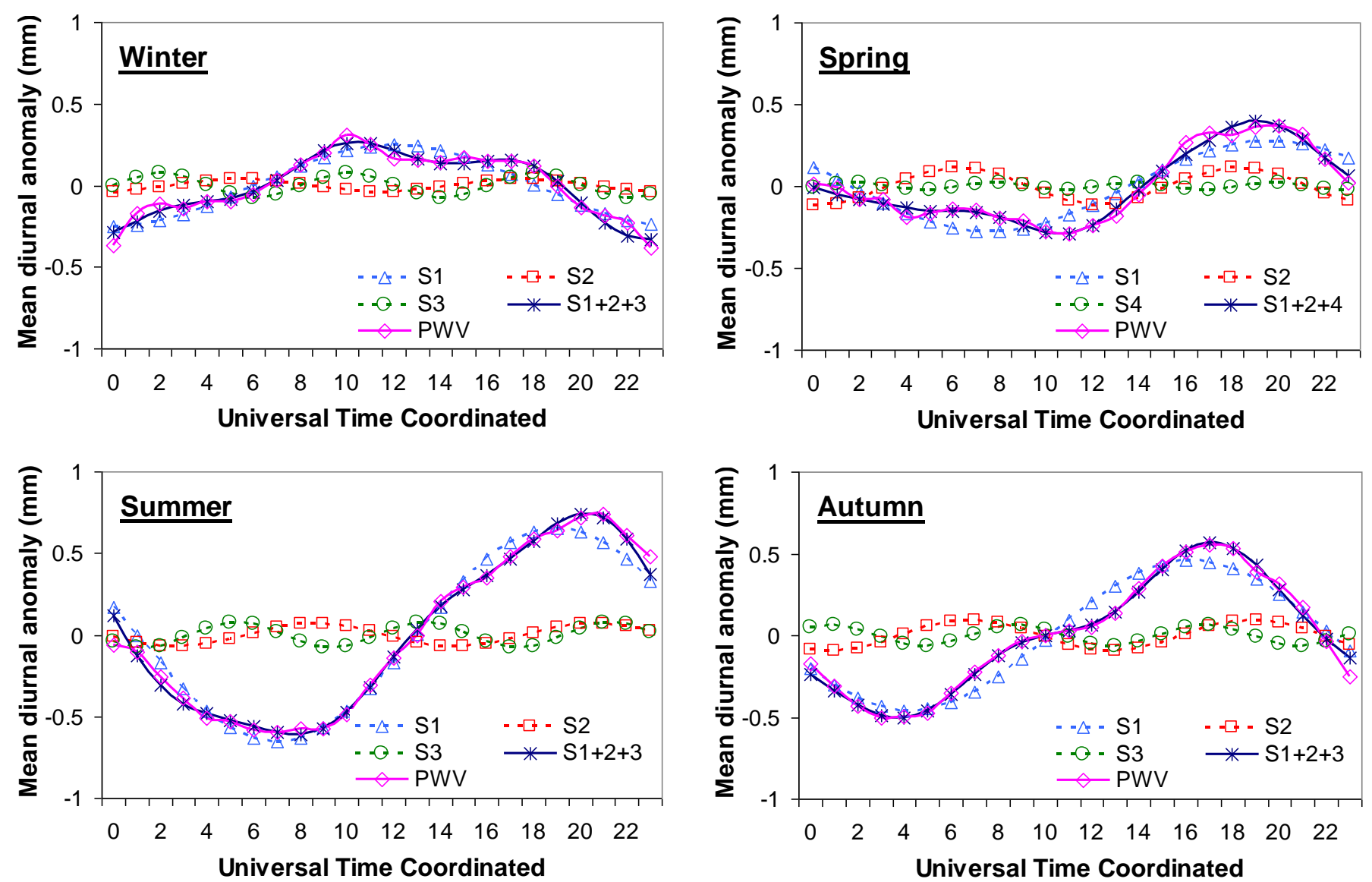

Fig. 4.- Seasonal mean diurnal cycle and harmonic analysis (see Fig. 3).

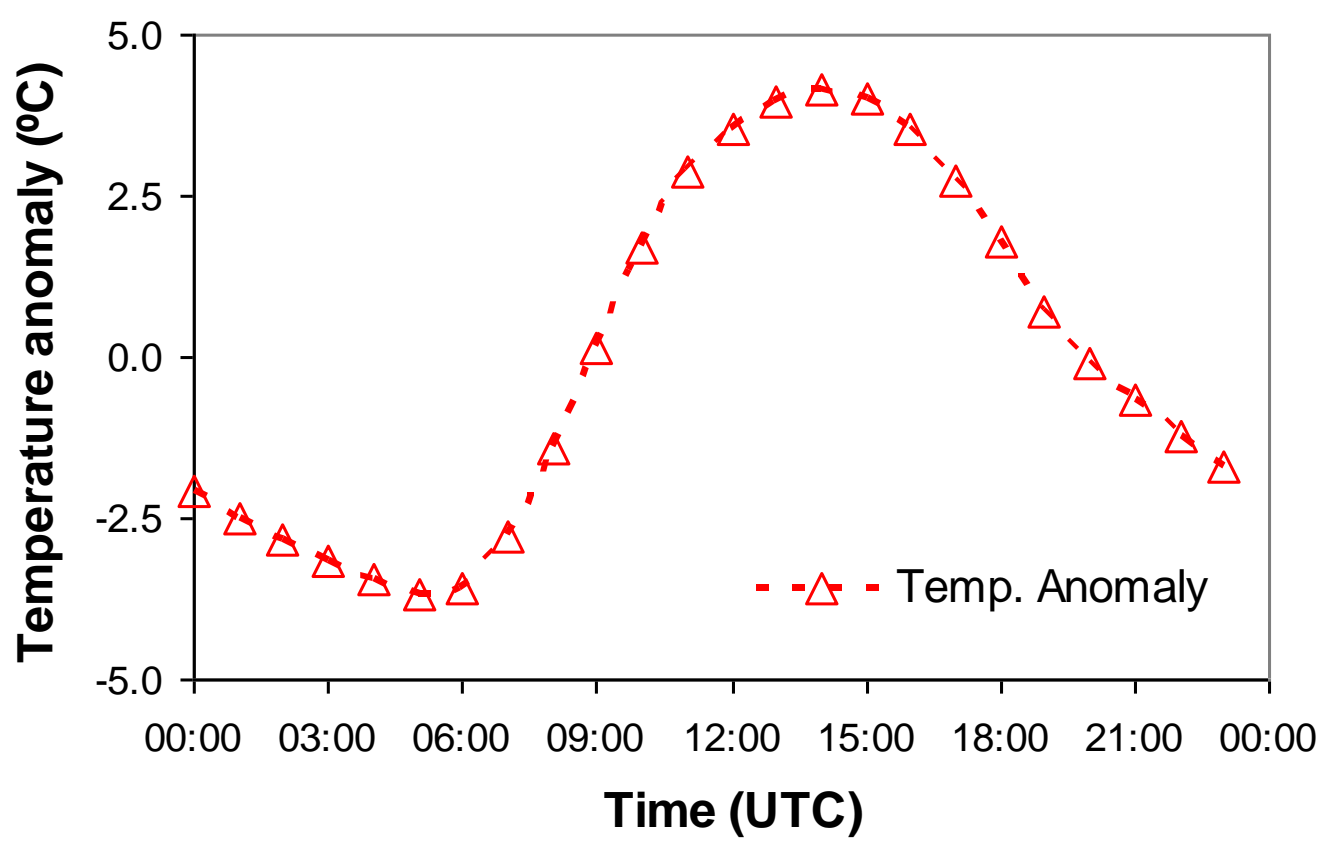

Fig. 5.- Annual average of the temperature diurnal cycle. 

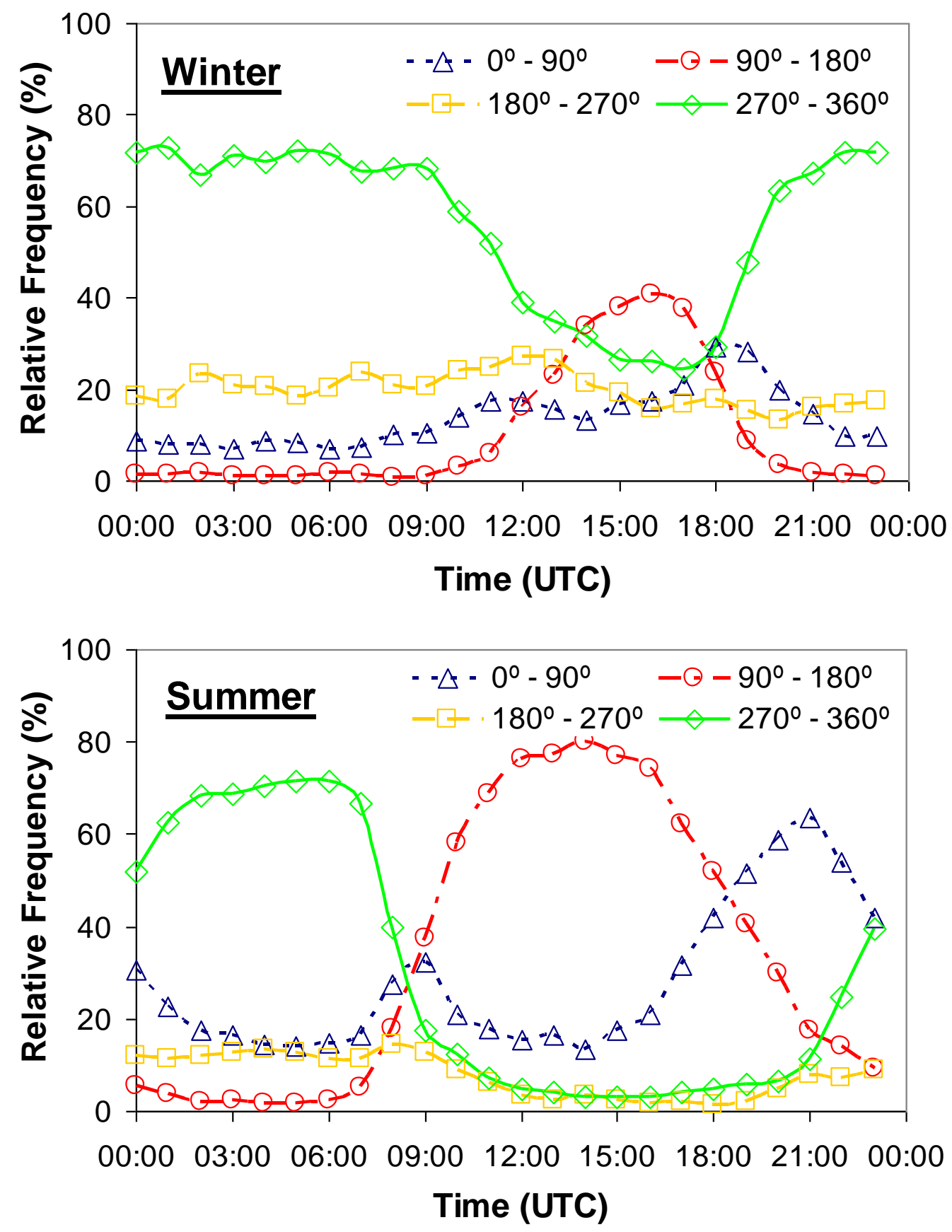

Fig. 6.- Seasonal diurnal cycles of the relative frequency (\%) of the wind direction at Valencia. The easterly winds blow from sea to land (sea breeze) and the westerly winds blow from land to sea (land breeze). 


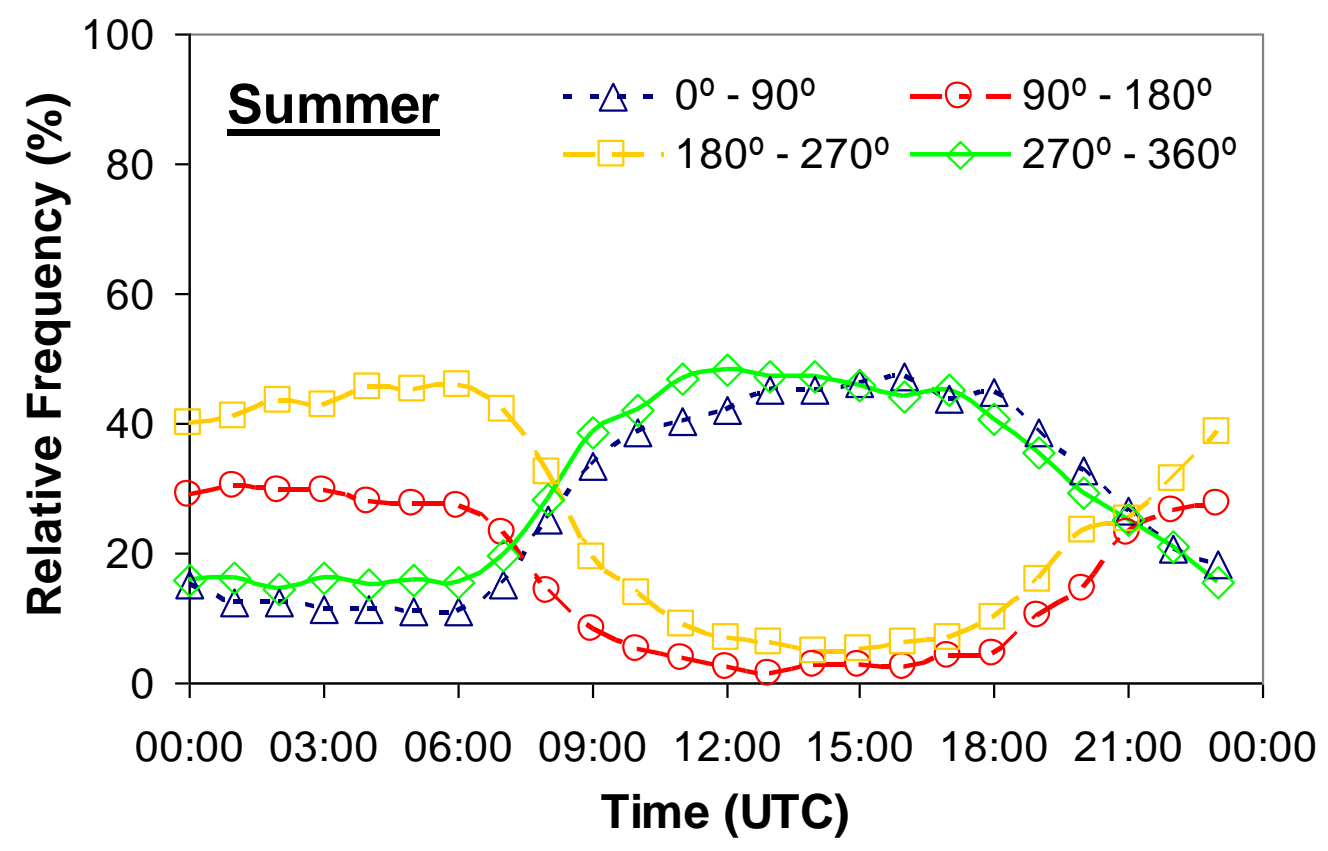

Fig. 7.- Summer diurnal cycle of the relative frequency (\%) of the wind direction at Santander. Northerly winds are of Atlantic origin.

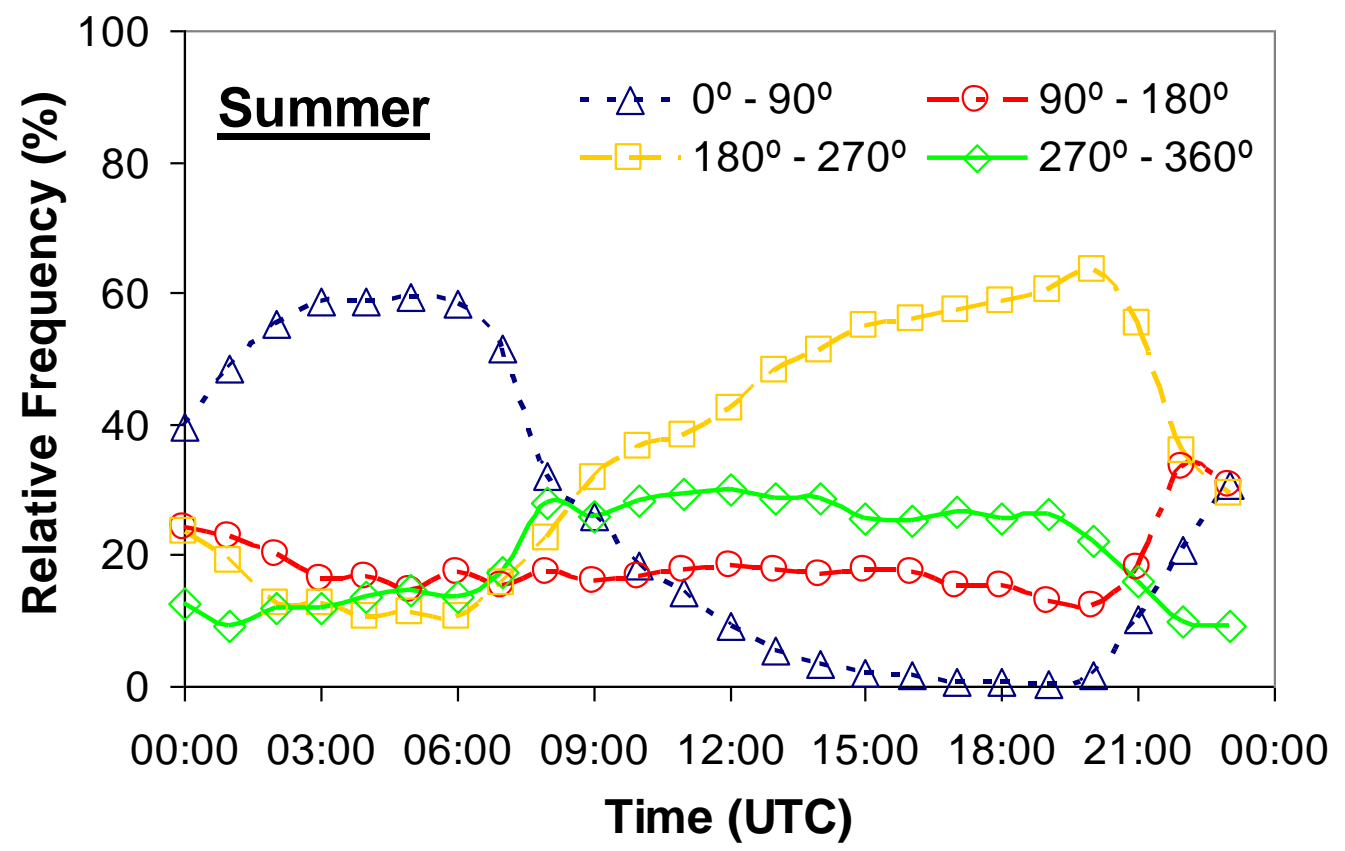

Fig. 8.- Summer diurnal cycle of the relative frequency of the wind direction at San Fernando. Westerly winds are of Atlantic origin and easterly winds have a Mediterranean influence. 


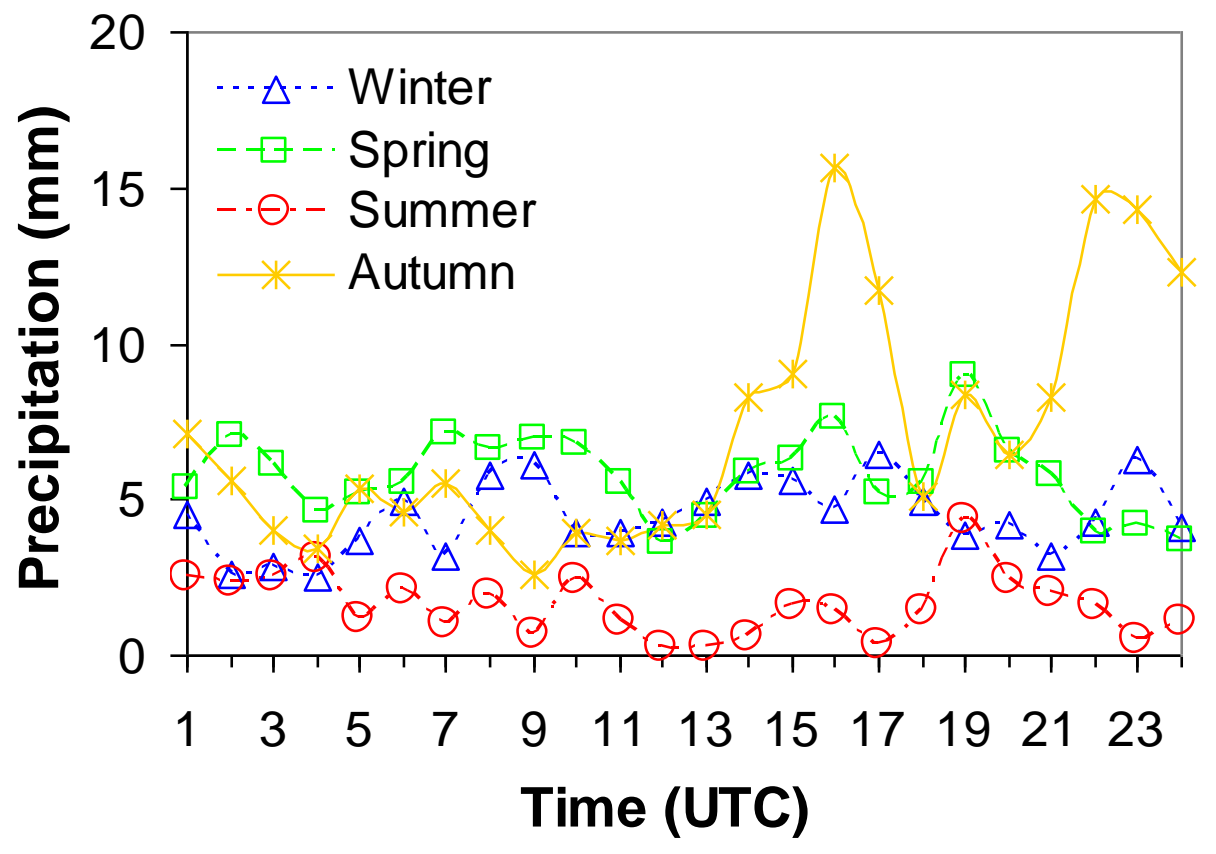

Fig. 9.- Time distribution of the mean cumulative seasonal rainfall at Valencia.

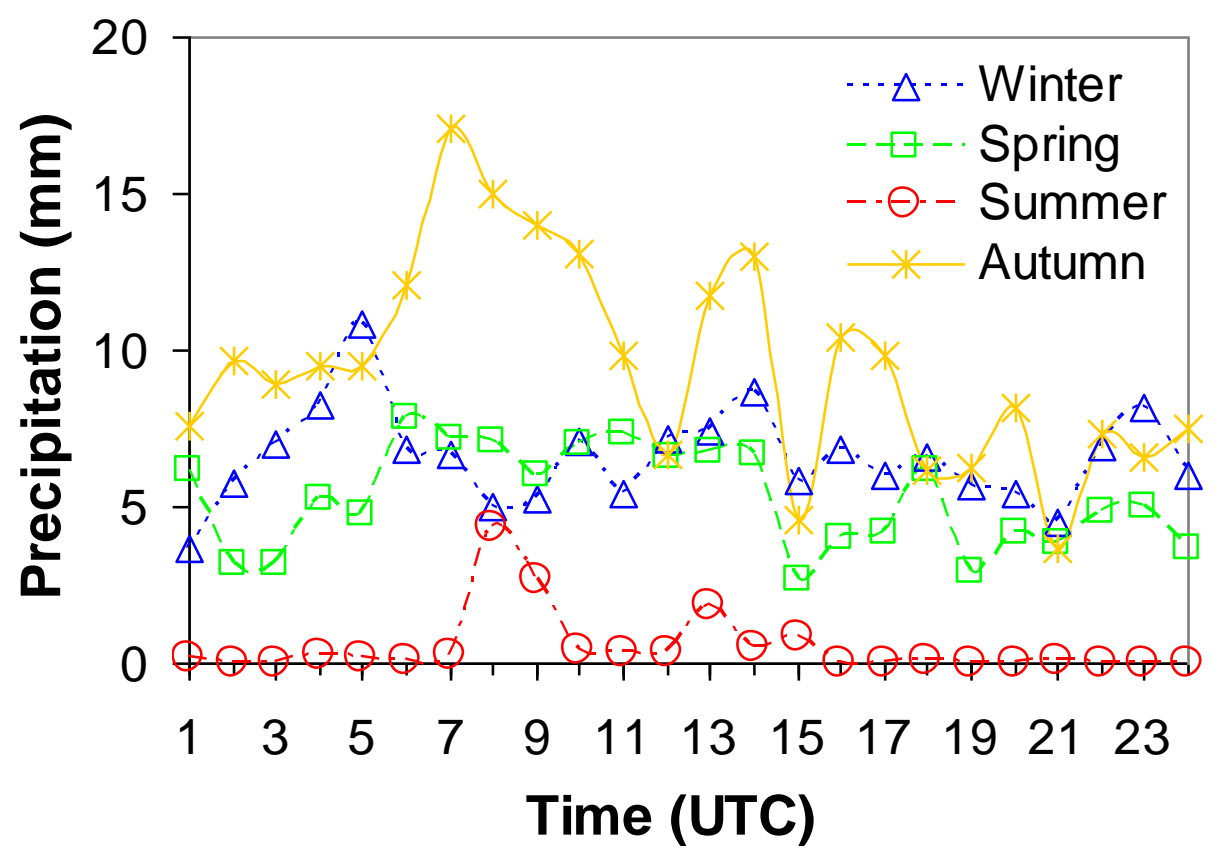

Fig. 10.- Time distribution of the mean cumulative seasonal rainfall at San Fernando. 